\title{
The Insurance Market in Kazakhstan
}

\section{Valikhan Kaliyev}

JSC "Life Insurance Company" State Annuity Company ", Director of the Department settlement payments Master of Economics and Business, 010000, Sh. Kudayberdyuly 25/1 square. ap. 28; Email: vkaliyev@bk.ru

\section{Doi:10.5901/mjss.2016.v7n3p190}

\begin{abstract}
In modern society, the insurance is a necessary element of production relations. The specific of the insurance activity is directly connected with compensation of material expenses due to the violation of social reproduction. The violation of social reproduction can occur due to the various negative reasons, such as natural disasters, fires, explosions, illegal activity of the third parties, etc. Society has to carry out a complex of preventive measures as protection against negative impacts of these events. If they don't lead to the necessary result, the requirement appears in compensation of caused injury to property and restoration of the process of social reproduction.
\end{abstract}

Keywords: Insurance market, business struggle, compulsory insurance, services.

\section{Introduction}

The subjects of the insurance business take an important place in the organization of insurance process: the production and the realization of specific goods, in other words, the insurance service is carried out through them. However, at the present time, the great value is attached only to one of the subjects - insurance enterprises whereas other three subjects of insurance business such as the society of a mutual insurance, insurance brokers and actuaries are insufficiently studied. Though, the international practice shows that full effective functioning of the insurance market requires the development of all subjects of the insurance business. Each subject has to occupy «niche" in the insurance market and play the assigned part. National practice shows that, at the present time the mixture of functions and roles between subjects leads to inefficient use of the available resources and doesn't lead to the expected results in the form of the developed insurance culture of a population and, as a result, to high volumes of the insurance market. At the present stage of insurance development in Kazakhstan, a need appeared in accurate emphasis of the influence of insurance business subjects, determination of their functions, and places in providing with insurance protection, for better management of insurance payments and, on this basis, further increase of economic efficiency of insurance enterprise. These ideas determine the relevance of the chosen subject of the thesis research.

\subsection{Literature review}

Many aspects of the essence and functioning of the insurance market were already considered by such scientistseconomists as Vorobyev P.V., Kachalovaye.Sh., Laykov A.Yu., Martynov A.A., Nikolenko N.P., Orlanyuk-Malitskaya JI.A., Rusakovao.I., Samarukhav.I., Serebrovskiyv.I., Raykherv.K., Reytmanl.I., Sukhov C.B., Turbinak.E., Fedorovat.A, Shakhovv.V., Yuldashevr.G., also national scientists such as A. Alimbayev, S. Alpysbayeva, U. Baymuratov, M. Kenzheguzin, A. Koshanov, K. Sagadiyev, O. Sabden, T. Pritvorova.

\subsection{Objectives and hypotheses}

The object of dissertation research is the insurance market and functioning of insurance entities.

The subject of the research is the financial relations arising between insurance entities and other participants of the insurance market in the process of its development.

Working hypothesis of the research is the assumption that the activity of the insurance entities has an impact on the development of the insurance market. Therefore, there is a need to investigate functioning of the insurance entities and make recommendations about their increase of efficiency of insurance payments. 


\section{Methods and Sample}

The methods of the comparative and system analysis of activity of the insurance entities in the national and international insurance markets were used in the process of the thesis research. The methods of the economic analysis, modeling and planning, scientific abstraction, economical and statistical methods of information collection and processing were used to achieve the aim of thesis research.

\subsection{The insurance market as a system of economic intercourse}

At the present stage of development of the equipment and science, the risk component of social reproduction is determined not only by factors of a natural origin but also more difficult mechanisms of production relations. The increasing scales of social reproduction in the international aspect gradually create conditions for the increase of probability of the advent of negative events. The entrepreneurial risks increase with the gradual development of the market relations. The development of scientific-and-technological advance caused the growth of technological hazards (environmental contamination, the increase of explosion hazard), the growth of accident risk and injury rate at the place of production. At last, the growth of the social and international conflicts is presented in the social environment which leads to a significant damage of separate manufacture and the whole state.

V. I. Serebrovsky defined that a main objective of the insurance is the satisfaction of property needs of the insurants (Serebrovsky V. I., 1927). At the same time, he noted that this objective has to be connected with the occurrence of accidental circumstances. The accidental character qualifies the happened event as insurance, thus, giving the possibility to consider the used ways of compensation of damage in money terms as the installment insurance compensation. In the absence of accidental character of insured event, the need in application of insurance institute is excluded, as it is possible to satisfy the property requirements in other ways, which are used in society for a long period of time. For example the realization of production activity, trade relations, the procedures of exchange and transfer by way of gift, etc.

I.I. Stepanov considered the insurance through its saving function, thus, noting the distinctions between insurance and saving: "insurance assumes the means which are specially intended to avoid consequences of the infelicitous occasion, as distinct from simple saving in case of monetary need. The insurance is the independent economic activity expressed in the saving which is specially intended to avoid possible destruction of values from infelicitous occasion" (Stepanov I.I., 1875).

V. K. Raykher noted that insurance can be defined as an organization form of the centralized insurance fund at the expense of the decentralized sources such as installments of participants of this fund (Raykher V. K., 1947). The insurant has to bring established installments in advance in strictly certain size and certain time in order not to lose the acquired rights owing to the purchase of insurance service. Whereas, the decision to do savings, «to save for a rainy day" is often carried out untimely and with some breaks. At implementation of savings, people are not limited in the usage of their finances: they can be received at any time and in full. In insurance, the insurant can't receive the installments back at any time and in a full size without deduction of the insurer (except for the events stipulated by the insurance contract) (Vobly K.G., 1993).

The analysis of the insurance literature showed that there are no concurrent views concerning a definition of "the insurance market" at the moment. On the one hand, it is a positive factor which shows that the insurance science is in continuous development and search. On the other hand, the correct development and understanding of the processes in the insurance market require complete and adequate definition of such fundamental concept as "the insurance market".

The interesting definition of the insurance market is represented in the economic dictionary: "the insurance market is a system of the economic relations arising under the conditions of the purchase and sale of specific goods or in another word "an insurance cover" in the course of satisfaction of public needs for insurance protection" (Rayzberg B. A., 2006). In this definition, there is no concept of insurance service; however, the authors specify that the economic relations arise round the specific goods which are called "insurance cover". In our opinion, the consideration of the insurance relations is possible from the point of view of the realization of goods. However, from the economic point of view, the supply and demand in the insurance market arise round the insurance service, and in turn, the market relates to the services sector.

Analyzing the above-stated opinions of famous scientists, it is possible to identify both coincidences and contradictions. A. A. Gvozdenko uses the most capacious definition of "insurance service», in this case, that is more preferable than the insurance protection. However, the insurance service finds its reflection in protection of property interests of insurants. Accordingly, considering the object of a purchase and sales, it is necessary to designate the insurance service. In confirmation of such point of view it is possible to give the opinion of D. Bland who estimates the 
insurance as the industry of services (Sost. D. B., 2008). He represents four concepts which describe the insurance role in the market economy are the cost, protection, risk and service. According to his opinion, the most important concept is the service.

In all definitions, it is possible to notice that the insurance market is defined either as a system, or as a structure. According to the explanatory dictionary of $\mathrm{D}$. N. Ushakov, the system is the device or the structure which represents the unity of naturally located and functioning parts (Ushakov D. N., 2000).

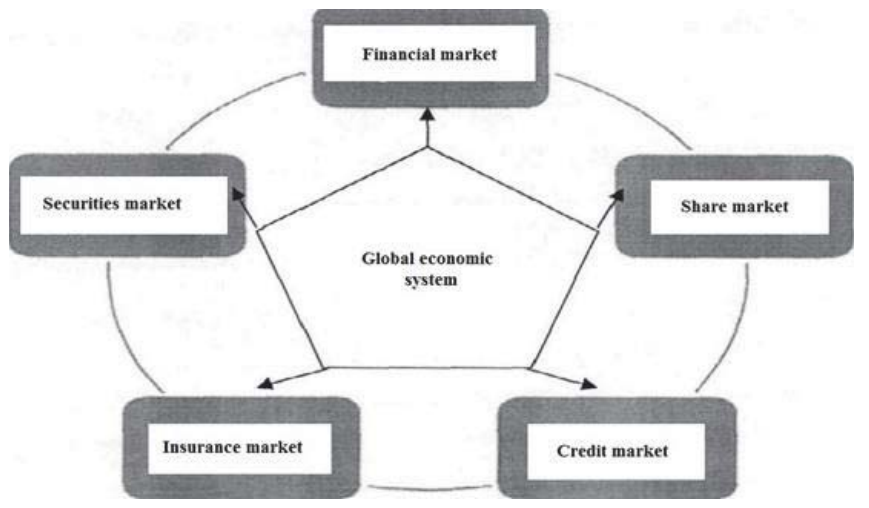

Figure 1. Global economic system

The set of discussions concerning the organization of the insurance relations appears during the process of consideration of the insurance market as a part of the economic system. Firstly, most insurants, as a rule, don't receive the invested money back. Secondly, in a case of an insurance event, a part of insurants can receive insurance funds which can exceed originally paid insurance premiums. Thus, redistribution of the accumulated money happens in the insurance market. Therefore, the distinctive feature of the insurance is the delay between execution of the insurance contract, i.e. accumulation of funds, and provision of the insurance service, i.e. the redistribution of these funds (Sultanova L.M, The insurance market of Kazakhstan).

The insurance markets carry out the functions of credit and investment institutes. The insurance enterprises take the second place after the credit organizations according to the size of assets and volumes of investment. For example, according to the number of clients and borrowed funds, in our country the leader in banking system is the National bank of the Republic of Kazakhstan. The leader in the insurance system is the "Eurasia" insurance company giving a place to characteristics of the National bank. In December, 2014, the group of the five leaders didn't undergo changes: "Eurasia" insurance company traditionally holds superiority during the whole year, occupying $16,9 \%$ of the market; "HalykKazakhinstrakh" holds the second place with 13,5\%; on the third place is "NOMAD Insurance " with 7,5\% ; the fourth position was taken by " Kaspi Insurance" with 7,1\%; and "Oil Insurance Company" finishes the five leaders with 6,3\% from the total volume of share of profits. The specific character of the insurance relations allows using the accumulated funds for investing into the securities market (for example, insurance premiums can be used according to long-dated cash-value life insurance). The commercial banks not always have such opportunities because they often use short-term funds.

Therefore, the insurance enterprise holds a paramount position on the economic market. Under the condition of existence of the balanced insurance portfolio, the accumulation of funds as the received insurance premiums, and the additional income from active transactions (investment, sponsorship, etc.) will considerably exceed the sum of insurance payments to the clients of the organization. This specific character of the activity allow insurers to increase the net profit and carry out the investments into government programs, securities (the government bonds, shares, bills of credit) and bank deposits, etc.

According to the territorial criterion we can emphasize local (regional), national (internal) and international (external) insurance markets:

- the local market - the insurance relations occur within one region;

- the national market - the expanded insurance relations occurring within the state;

- the international market - deleting of the state borders, insurance relations are carried out at the level of the 
world economy.

The business struggle induces the insurance enterprises to develop and introduce new types of insurance, constantly improve them, expand the range and cover extra segments of the insurance market. Besides, the business struggle stimulates the development of insurance models such as the model of direct insurance and the insurance model with the involvement of the intermediary. According to this, it is possible to draw an important conclusion: the insurance as the sphere of economic activity is primary in this chain. The implementation of this activity happens in the insurance market, and given activity bears a name of the insurance business. The understanding of the processes happening in insurance requires a clear understanding of these three elements.

The specific goods offered on the insurance market is the insurance service which has some parameters. The first parameter is the value in use, and the second is the exchanged value. The value in use is a providing the insurer with the insurance protection which gets a form of the insurance cover. The exchanged value is the price of the insurance service which is expressed in the insurance tariff and installment.

As a rule, the price of the insurance service is presented in the insurance tariff, expressed as a percentage of the insured sum. The size of the tariff is defined on a competitive basis through the demand and supply matching. The minimal boundary of a tariff is determined by a loss ratio according to the concrete type of insurance, i.e. the size of the expected insurance premiums and the subsequent insurance payments. The upper boundary is determined by uninsurable expenses (a salary to the employees, expenses on conducting business) and the expected profit. If the size of the insurance tariff is excessively high in comparison with competitors, then the insurance enterprise can lose the client due to the non-competitive price. The size of the insurance tariff of concrete insurance enterprise depends on the loss ratio of the types of insurance, the size and the equation of the insurance portfolio, the expected profit, the size of uninsurable expenses.

According to the analysis of insurance literature and practice in the developed insurance market, today, it is possible to emphasize two big groups of insurance services: the insurance of private persons (citizens) and the insurance of legal entities (enterprises and private entrepreneurs).

The insurance of private persons can be divided into such types as the personal insurance, the insurance of property and the liability insurance. The row of types of insurance for legal entities will be a little different: personal insurance, insurance of property, responsibility and entrepreneurial risks.

The position on the insurance market is determined by the set of factors. The most important factors are a risk situation, financial incomes of insurants, the insurance tariff, the offer of insurance services. The conditions of realization of the insurance service developing in concrete region at present time are called conjuncture of the insurance market. Firstly, the conjuncture characterizes the level of the supply and demand of the insurance services. According to this, the conjuncture can be favorable or unfavorable for both the insurer and the insurant.

\subsection{At the present time, the certificate of insurance can also be taken over the Internet in electronic form. According to financial supervision of the National Bank of Kazakhstan, since June 1st, 2015, 35 insurance and reinsurance companies work in Kazakhstan, each company tries to create the most comfortable conditions for each client.}

According to the foreign experts, the online insurance can be one of dominated the sales channels. The rapid development of the on-line stores in the world dictates the terms of mobility, efficiency and service. The advantages of receiving online services are beyond controversy. The possibility of receiving online service allows saving a lot of time on the insurance market. The trip to the office of the insurer and consultation with the manager can take some hours, and filling in an application on the site takes several minutes. The opportunity to study insurance conditions attentively is no less important, and the insurance calculator will give the insurance sum at once therefore, it is possible to reconsider the sum of payment of the certificate of insurance in variations convenient for you, choosing optimal conditions. The level of safety of the insurance calculator is as high as a bank safety.

Moreover, many insurance companies according to the online purchase of the certificates of insurance have to provide essential discounts to the clients. Because, ordering certificate of insurance over the internet, you considerably save funds of the insurer who doesn't spend funds on the staff and transportation payments. Mainly, such services are provided for private persons as the enterprise clients demand the individual approach in service and payments.

Thus, having considered the essence of the insurance market according to the point of view of various scientists, the author came to a conclusion that the majority of the points of view don't consider a role of the subjects of insurance business in the insurance market. Accordingly, it doesn't find reflection in definitions of «the insurance market". Thus, the author added the definition of the insurance market taking into account the activity of the subjects of insurance business.

The Republic of Kazakhstan is distinguished from the CIS countries by a high level of development of normative 
base and state regulation of the insurance market, in spite of the fact, that indicators of the premium income and insurance payments in Kazakhstan are still lower, than some neighbors of the CIS have. It provides a big guarantee of insurants in compensation of risk at the occurrence of an insured accident.

The insurance market of Kazakhstan can be called as one of the most dynamically developing in the CIS. It was promoted by the Program of development of the insurance market of the republic.

The insurance which is carried out by law is obligatory. Each type of obligatory insurance is a separate class of the insurance. The maintenance of each class of the obligatory insurance and additional requirements under the terms of its carrying out are fixed by law which regulates this class of the insurance.

The workers except for the working pensioners, independently self-employed people including the foreigners and stateless people who constantly live in the territory of the Republic of Kazakhstan and carry out the activity which brings the income in the territory of RK are subject to the obligatory social insurance.

Obligatory social insurance is subdivided into the following types:

1) the insurance in case of disability;

2) the insurance in case of the loss of breadwinner;

3) the insurance in case of the job loss.

The state guarantees to citizens the right to receive the social payments in cases of risk according to types of obligatory social insurance on the conditions established by the Law.

According to the experience of the countries with market economy, the mechanism of obligatory insurance is widely used by the state in order to maintain the social stability and acceleration of economy development.

The obligatory insurance of civil carrier's liability towards the passengers. The object of obligatory insurance of civil carrier's liability towards the passengers is the carrier's property interest connected with his duty established by the law of the RK to pay for damage caused to the life, health and property of passengers by means of implementation of insurance payments.

The obligatory insurance of the civil liability of public accountants and audit organizations. Object of obligatory insurance of civil liability of public accountants and audit organizations is the property interest of the public accountant and audit organization connected with their duty established by the civil legislation of RK to pay for damage caused to the audited subjects during the audit performance.

The obligatory insurance of civil liability of private notaries. The object of obligatory insurance of the civil liability of private notaries are the property interests of the private notary connected with its duty to pay for damage caused to the third parties during the notarization. The private notary is obliged to sign the contract of obligatory insurance of the private notary's liability in order to implement notarial actions.

The obligatory insurance of civil liability of the tour operator. According to the law, the object of the insurance is the property interest of tour operator connected with the duty established by the civil legislation of RK to pay for damage caused to the property interests and other interests of the tourist during realization of a tourist product by means of implementation of insurance payments.

The obligatory insurance of civil liability of owners of objects which are connected with the hazard of injury infliction to the third parties". Object of this type of insurance is the property interest of the owner of object connected with duty to pay for damage caused to the life, health and property of the third parties as a result of accident by means of implementation of insurance payments.

\section{Results and Discussions}

The theoretical relevance of the research is included in the term "the insurance market" from the point of view of activization of activity of the insurance entities, the addition of the definition of this term; specification of definition of the insurance entities; allocation of the stages of development of the insurance industry in Kazakhstan taking into account the emergence of the insurance entities; in the maintaining of the insurance agents into the list of the insurance entities of , and also inclusion of the associations of the insurance entities and the insurers into the elements of infrastructure.

The practical relevance is included in the possible use of the results of the work in activity of each the insurance entity according to the designated scheme of interaction of the insurance entity and consumers of the insurance services. Also results of the research can be applied at permission of the questions connected with further reforming of activity of these insurance entities in Kazakhstan. 


\section{Conclusion}

Relying on the above-stated arguments and the analysis, we can represent the definition of the insurance market. According to the author, the insurance market is a system of the economic relations regulated by the state which arises between its participants concerning production, realization of the insurance service by the subjects of insurance business involving the infrastructure elements, and also its consumption on the part of the demander.

The insurance market is included into the global economic system. Therefore, it is closely connected with financial and share markets, a banking system, etc. All abovementioned economic categories form the infrastructure of the market, i.e. a complex of legal organizational forms, which determine the movement of goods and services or complex of the institutes, systems, and services, the organizations which serve the market and carry out the certain functions in providing the normal mode of its functioning.

At the present time, in Kazakhstan market, the most part of insurance companies don't provide the whole complex of online insurance on their corporate site. They are limited by the consultations and the detailed description of their products. Therefore, today, the online - insurance in Kazakhstan is the list of the insurance, the insurance calculator, online consultant and leaving of an application for policy of insurance. If you order the certificate of insurance on the web site, the operator calls back, offers consultations, effects a policy of insurance and the express messenger delivers the certificate of insurance. After the payment you keep one copy for yourself or you should make out the policy at the office of the insurance company. It isn't online - insurance in a standard form. First of all, online insurance is a possibility of payment of the certificate of insurance and the execution of the contract directly over the web site of the company. The certificates of insurance have to be in electronic form and sent to the client by e-mail. The order of the certificate of insurance and payment by the plastic card and receiving of the certificate of insurance by email is a basis of the online service.

\section{References}

Rayzberg B. A.( 2006) Modern economic dictionary .M.: INFRA-M, . 495 pp.

Raykher V. K. (1947) Socio-historical types of insurance. - M, L.: Academy of Sciences of the USSR .282pp.

Serebrovsky V. I. (1927). Insurance. Under Agarkov M. M. and Wolf V. F. edition. M.: Finizdat NIF SSSR, 144pp.

Sost. D. B.( 2008) Insurance: principles and practice. The lane with English - M.: Finance and statistics. 416 pp.

Stepanov I.I.( 1875) Experience of the theory of the insurance contract. - Kazan, 245 pp.

Sultanova L.M. The insurance market of Kazakhstan.

Ushakov D. N. (2000) Russian Explanatory dictionary. M.: INFRA-M, 405 pp.

Vobly K.G.(1993) Bases of insurance economy .- M.: SO "Ankil", .227 pp. 